\title{
Il triennio rivoluzionario visto dalla Francia
}

\section{6-1799}

\section{Vittorio Criscuolo}

\section{(2) OpenEdition \\ 1 Journals}

\section{Édition électronique}

URL : https://journals.openedition.org/ahrf/1083

DOI : 10.4000/ahrf.1083

ISSN : 1952-403X

Éditeur :

Armand Colin, Société des études robespierristes

\section{Édition imprimée}

Date de publication : 1 mars 2001

Pagination : 150-152

ISSN : 0003-4436

\section{Référence électronique}

Vittorio Criscuolo, «II triennio rivoluzionario visto dalla Francia 1796-1799 », Annales historiques de la Révolution française [En ligne], 323 | janvier-mars 2001, mis en ligne le 10 avril 2006, consulté le 24 avril 2022. URL : http://journals.openedition.org/ahrf/1083 ; DOI : https://doi.org/10.4000/ahrf.1083

Ce document a été généré automatiquement le 24 avril 2022.

Tous droits réservés 


\title{
Il triennio rivoluzionario visto dalla Francia 1796-1799
}

\author{
Vittorio Criscuolo
}

\section{RÉFÉRENCE}

Michel Vovelle, Il triennio rivoluzionario visto dalla Francia 1796-1799, Guida editori (Collana Storici e storia), Napoli, 1999, a cura di Erica Joy Mannucci, traduzioni di Filiberto Agostini, Tukery Capra, Luigi Samarati e Vittorio Scotti Douglas.

1 Après les travaux fondamentaux d'un pionnier tel que Jacques Godechot, les historiens français n'ont plus montré un intérêt particulier pour l'histoire de l'Italie au cours de la période révolutionnaire. C'est pourquoi il faut saluer avec satisfaction l'apparition de ce livre, qui permet aux spécialistes et aux lecteurs italiens d'observer les protagonistes et les événements du triennio 1796-1799 par le regard pénétrant d'un véritable maître de l'historiographie française.

2 Si l'on excepte un compte rendu d'un livre d'Anna Maria Rao (Esuli. L'emigrazione politica italiana in Francia 1792-1802, Napoli 1992), tous les travaux recueillis dans ce volume sont des interventions aux célébrations du Bicentenaire organisées par diverses villes italiennes entre 1995 et 1997. Cependant ces textes ne présentent pas du tout de considérations de circonstance, et nous offrent au contraire une réfléxion très stimulante sur de nombreuses questions essentielles afin d'approfondir la compréhension historique du triennio.

3 En ce qui concerne les relations entre l'histoire italienne et la Révolution, un problème historique qui a toujours suscité dans la culture italienne des discussions acharnées, Vovelle reconnaît que les événéments français ont laissé dans l'histoire de la péninsule des traces plus profondes que dans les autres pays européens. Le bien-fondé de cette conclusion est attesté par le grand nombre de congrès, d'expositions, de commémorations, de livres consacrés aux célébrations de la Révolution, fruit d'un effort d'organisation dans lequel l'Italie n'a été inférieure qu'à la France. 
4 En nuançant des convictions bien enracinées dans l'historiographie italienne sur le XVIIIesiècle, Vovelle nous rappelle qu'en 1789 la phase des réformes d'en haut s'était désormais terminée dans les divers états de la péninsule. C'est pourquoi l'influence de la France révolutionnaire a eu la possibilité d'agir en profondeur:

«L'Italie de 1789 a de commun avec la France, même si avec des traits particuliers, une expérience politique récente que, même au risque d'une simplification excessive, je définirais l'échec du despotisme éclairé ou de la réforme d'en haut».

6 À partir de ce moment, la vie politique et intellectuelle de la péninsule s'est régénérée grâce à l'exemple extraordinaire de la Révolution, mais elle n'a jamais perdu sa propre spécificité, si bien que les idéaux et les projets des démocrates italiens n'ont jamais été «le calque ou la copie du modèle français». M.Vovelle souligne opportunément l'originalité de l'expérience italienne, qu'il faut considérer comme «une révolution à juste titre dans le contexte de la grande Révolution». Naturellement tout le cours de l'histoire italienne a été conditionné par le fait que les armées françaises descendirent dans la péninsule après la chute du gouvernement révolutionnaire. À partir de cette constatation, M.Vovelle nous offre un tableau très équilibré des forces qui se sont confrontées au cours du triennio 1796-1799: les groupes démocratiques, contrecarrés par les autorités françaises et par le Directoire, les modérés qui ont gouverné la plupart des républiques-sœurs, les oppositions qui donnèrent lieu souvent au phènomène de l'insurrection contre-révolutionnaire.

7 Le livre est très intéressant aussi en raison de l'attention qu'il réserve à l'histoire des images, un domaine de recherche auquel M.Vovelle et ses élèves se sont consacrés depuis quelques années. On peut trouver en effet à la fin du volume la reproduction d'un certain nombre d'estampes et de gravures: l'analyse de ces témoignages montre que l'image et la caricature sont devenues au cours du triennio un nouveau langage politique, que les ennemis mêmes de la Révolution n'ont pas hésité à utiliser.

8 M.Vovelle n'ignore pas le poids de l'occupation militaire, les rapines et les déprédations des commissaires civils et des généraux, les coups d'État imposés aux républiques-sœurs. Deux travaux très intéressants sont consacrés à la cession de Venise à l'Autriche, «amer démenti de la promesse révolutionnaire d'émanciper les peuples et de respecter leur droit d'autodétermination». Dans ces deux essais M.Vovelle analyse respectivement les humeurs de l'opinion publique française devant la chute de la république vénitienne, en utilisant entre autres les rapports de police publiés à la fin du siècle dernier par Alphonse Aulard, et les jugements de l'historiographie française sur le traité de Campoformio.

9 Le livre s'occupe aussi de la figure de Bonaparte et, en utilisant encore divers témoignages iconographiques, met en lumière la naissance de la légende napoléonienne en Italie "grâce à une des manipulations majeures de l'opinion publique de l'histoire moderne». Il faut signaler surtout l'essai qui analyse avec une grande finesse les nombreuses implications politiques, idéologiques et psychologiques des relations entre Napoléon et l'Italie. M.Vovelle pense que les Italiens ont gardé une opinion plus positive de Napoléon que les Français, parce qu'il représente à leurs yeux un facteur important de modernisation de la péninsule. Sans doute l'historien français se rattache ici à la tradition républicaine qui n'a jamais pardonné à Napoléon le 18 Brumaire. Il faut rappeler aussi que les positions italiennes devant l'œuvre de Napoléon ont été toujours conditionnées négativement par le souvenir de la complète soumission de la péninsule à l'Empire, si bien que l'on ne retrouve pas dans la vie politique et 
culturelle de l'Italie au XIxesiècle l'enthousiasme que la légende napoléonienne a excité ailleurs.

10 En se trouvant à reparcourir les chemins par lesquels ses compatriotes descendirent il y a deux siècles dans la péninsule, M.Vovelle se demande, avec ironie, en quelle qualité un historien français peut se présenter aujourd'hui à ses amis italiens, afin de commémorer la présence française en Italie: sera-t-il considéré comme un «patriote missionnaire», ou plutôt comme un émule des commissaires du Directoire, venu piller jusqu'à la mémoire historique du pays conquis? En fait il n'est pas difficile de reconnaître dans son intérêt pour l'histoire italienne, dans sa sympathie sincère pour les événements des républiques-sœurs un certain vestige de cette fraternité républicaine qui anima tant de protagonistes de cette période, par-deçà ainsi qu'au-delà des Alpes. 